\title{
Single-Pulse Shock Tube Studies on the Stability of 1-Phenyl-2-butene and the Strength of the Vinyl-H Bond in Propene $^{\dagger}$
}

\author{
J. P. Cui, ${ }^{\ddagger}$ Y. Z. He, ${ }^{\ddagger}$ and W. Tsang* \\ Chemical Kinetics Division, National Bureau of Standards, Gaithersburg, Maryland 20899 \\ Received September 17, 1987. Revised Manuscript Received May 12, 1988
}

\begin{abstract}
1-Phenyl-2-butene (1-PHB-2) has been decomposed in single-pulse shock tube experiments. Acetylene formation is used as a measure of the rate of cleavage of the benzyl-vinyl $\mathrm{C}-\mathrm{C}$ bond. The rate expression for this reaction has been found to be $k(1-\mathrm{PHB}-2 \rightarrow$ benzyl + propenyl $)=2.4 \times$ $10^{16}[\exp (-43780 / T)] / \mathrm{s}$ over the temperature range $1100-1220 \mathrm{~K}$ and pressures of $2.5-3.5 \mathrm{~atm}$. Our results are consistent with a bond dissociation energy for the primary vinyl $\mathrm{C}-\mathrm{H}$ bond in propylene of $459 \pm 10 \mathrm{~kJ} / \mathrm{mol}$.
\end{abstract}

\section{Introduction}

This paper is concerned with the strength of the primary vinyl $\mathrm{C}-\mathrm{H}$ bond in propylene. It should provide additional information of the energy of the vinyl $\mathrm{C}-\mathrm{H}$ bond in ethylene. Within the past year there have been values ranging from 435 to $495 \mathrm{~kJ} / \mathrm{mol}^{1,2}$ Any effect from methyl substitution will be far smaller than the spread of such numbers. The importance of the value of this quantity is due to the evidence ${ }^{3}$ that vinyl radicals are key reactive intermediates for soot formation. Unfortunately, there is at present almost no rate data on vinyl radical reactions, and the uncertainty with regard to its heat of formation prevents even the most rudimentary efforts at estimation. For example, at $655 \mathrm{~K}$ a $12 \mathrm{~kJ} / \mathrm{mol}$ uncertainty in the activation energy for a given process will lead to an uncertainty of a factor of 10 in the rate constant.

The experiments are carried out in a heated single-pulse shock tube. ${ }^{4}$ Our target molecule is 1-phenyl-2-butene (1-PHB-2). The choice of this molecule is dictated by the weakening of the vinyl $\mathrm{C}-\mathrm{C}$ bond by benzyl resonance and the decreased stability of the propenyl radical compared to that of the vinyl radical itself (had we chosen to work with allylbenzene). Although the rate constants for vinyl-benzyl bond cleavage are still very much smaller than those for the alkane and alkene decompositions that we have hitherto studied, ${ }^{5}$ benzyl resonance raises the values (by reduction of the activation energy) to a range that is more convenient for our experiments. Furthermore, the formation of acetylene, from the decomposition of the propenyl radical as a result of $\beta-\mathrm{C}-\mathrm{C}$ bond fission, as a unique reaction product, provides us with a special marker. We estimate that the highest possible activation energy for propenyl radical decomposition is on the order of 163 $\mathrm{kJ} / \mathrm{mol}$. This is based on the rate data for methyl addition to acetylene ${ }^{6}$ and the thermochemistry assuming the lowest proposed vinyl-H bond strength. This implies maximum lifetimes at our reaction temperatures of $20-30 \mu \mathrm{s}$, which is far shorter than the heating time of $500 \mu \mathrm{s}$. A higher vinyl-H bond strength will lead to shorter lifetimes.

There have been no previous studies on 1-PHB-2 decomposition. In Scheme I, we outline all possible com-

\footnotetext{
${ }^{\dagger}$ Presented at the Symposium on Advances in Soot Chemistry, 194th National Meeting of the American Chemical Society, New Orleans, LA, August 31-September 4, 1987.

‡ Guest scientists. Permanent address: Institute of Mechanics, Academia Sinica, Beijing, China.
}

Scheme I. Bond-Breaking Steps in 1-Phenyl-2-butene Decomposition

$$
\begin{array}{rlr}
\text { a. } \mathrm{C}-\mathrm{H} \text { bond split } & \multicolumn{1}{c}{\mathrm{kJ} / \mathrm{mol}} \\
\mathrm{C}_{6} \mathrm{H}_{5} \mathrm{CH}_{2} \mathrm{CH}=\mathrm{CHCH}_{3} & \rightarrow \mathrm{C}_{6} \mathrm{H}_{5} \mathrm{CHCH}=\mathrm{CHCH}_{3}+\mathrm{H} & 356 \\
& \rightarrow \mathrm{C}_{6} \mathrm{H}_{5} \mathrm{CH}_{2} \mathrm{CH}=\mathrm{CHCH}_{2}+\mathrm{H} & 377 \\
& \rightarrow \mathrm{C}_{6} \mathrm{H}_{5} \mathrm{CH}_{2} \mathrm{C}=\mathrm{CHCH}_{3}+\mathrm{H} & 435-495 \\
& \rightarrow \mathrm{C}_{6} \mathrm{H}_{5} \mathrm{CH}_{2} \mathrm{CH}=\mathrm{CCH}_{3}+\mathrm{H} & 435-495 \\
& \rightarrow \mathrm{C}_{6} \mathrm{H}_{4} \mathrm{CH}_{2} \mathrm{CH}=\mathrm{CHCH}_{3}+\mathrm{H} & 460 \\
\text { b. C-C bond split } & \\
\mathrm{C}_{6} \mathrm{H}_{5} \mathrm{CH}_{2} \mathrm{CH}=\mathrm{CHCH}_{3} & \rightarrow \mathrm{C}_{6} \mathrm{H}_{5}+\mathrm{CH}_{2} \mathrm{CH}=\mathrm{CHCH}_{3} & 376 \\
& \rightarrow \mathrm{C}_{6} \mathrm{H}_{5} \mathrm{CH}_{2}+\mathrm{CH}=\mathrm{CHCH} & 335-395 \\
& \rightarrow \mathrm{C}_{6} \mathrm{H}_{5} \mathrm{CH}_{2} \mathrm{CH}=\mathrm{CH}+\mathrm{CH}_{3} & 389-449
\end{array}
$$

${ }^{a}$ Values are estimates based on ref 7 and 5 and discussion in text.

petitive unimolecular decomposition processes. Also included are the bond energies. These values will be very close to the activation energies for the breaking of these bonds. For the bond strengths of the bonds that are adjacent to the double bond we give a range of values. They cover the full range of vinylic bond strengths that we have mentioned earlier. Since the key uncertainty is the strength of the bond adjacent to the vinyl group, internal consistency requires that the choice of a value for the strength of one of these bonds immediately sets the values for the others. The values for the non-vinylic bonds are estimates based on data from published sources. ${ }^{7}$ Aside from the activation energy, the other factor that controls the rate expression for unimolecular decomposition are the $A$ factors. Over the temperature range of interest, we have found, ${ }^{5}$ for $\mathrm{C}-\mathrm{C}$ bond cleavage, $A$ factors per bond in the range of $3 \times 10^{15}$ to $3 \times 10^{16} \mathrm{~s}^{-1}$. For $\mathrm{C}-\mathrm{H}$ bond cleavage, published values of the reverse combination rate lead to $A$ factors per $\mathrm{C}-\mathrm{H}$ bond in the $5 \times 10^{14}$ to $2 \times 10^{15} \mathrm{~s}^{-18,9}$

(1) Shiromaru, H.; Achiba, Y.; Kimura, K.; Lee, Y. T. J. Phys. Chem. $1987,91,17$

(2) Kiefer, J. H.; Wei, H. C.; Kern, R. D.; Wu, C. H. Int. J. Chem. Kinet. 1985, 17, 225.

(3) Frenklach, M.; Gardiner, W. C.; Clary, D.; Stein, S. E. Twentieth Symposium (International) on Combustion; The Combustion Institute: Pittsburgh, PA, 1984; p 887.

(4) Robaugh, D.; Tsang, W. J. Phys. Chem. 1986, 90, 5363.

(5) Tsang, W. in Shock Waves in Chemistry; Lifshitz, A., Ed.; Marcel Dekker: New York, 1981; p 59.

(6) Kerr, J. A.; Parsonage, M. J. Evaluated Kinetic Data on Gas Phase Addition Reactions; Butterworths: London, 1972, pg.166. 493

(7) McMillen, D. F.; Golden, D. M. Annu. Rev. Phys. Chem. 1982, 33, 
Scheme II. Hydrogen and Methyl Attack on 1-Phenyl-2-butene

a. displacement

$$
\begin{aligned}
\mathrm{C}_{6} \mathrm{H}_{5} \mathrm{CH}_{2} \mathrm{CH}=\mathrm{CHCH}_{3}+\mathrm{H} & \rightarrow \mathrm{C}_{6} \mathrm{H}_{6}+\mathrm{CH}_{2} \mathrm{CH}=\mathrm{CHCH}_{3} \\
& \rightarrow \mathrm{C}_{6} \mathrm{H}_{5} \mathrm{CH}_{2}+\mathrm{C}_{3} \mathrm{H}_{6} \\
& \rightarrow \mathrm{C}_{6} \mathrm{H}_{5} \mathrm{CH}_{2} \mathrm{CH}=\mathrm{CH}_{2}+\mathrm{CH}_{3} \\
\mathrm{C}_{6} \mathrm{H}_{5} \mathrm{CH}_{2} \mathrm{CH}=\mathrm{CHCH}_{3}+\mathrm{CH}_{3} & \rightarrow \mathrm{C}_{6} \mathrm{H}_{5} \mathrm{CH}_{3}+\mathrm{CH}_{2} \mathrm{CH}=\mathrm{CHCH}_{3} \\
& \rightarrow \mathrm{C}_{6} \mathrm{H}_{5} \mathrm{CH}_{2}+\mathrm{CH}_{3} \mathrm{CH}=\mathrm{CHCH}_{3}
\end{aligned}
$$

b. abstraction

$$
\begin{aligned}
\mathrm{C}_{6} \mathrm{H}_{5} \mathrm{CH}_{2} \mathrm{CH}=\mathrm{CHCH}_{3}+\mathrm{H}, \rightarrow & \mathrm{C}_{6} \mathrm{H}_{4} \mathrm{CH}_{2} \mathrm{CH}=\mathrm{CHCH}_{3}+ \\
\mathrm{CH}_{3} \text {, or phenyl type } & \mathrm{H}_{2}, \mathrm{CH}_{4} \text {, benzenes } \\
\rightarrow & \mathrm{C}_{6} \mathrm{H}_{5} \mathrm{CHCH}=\mathrm{CHCH}_{3}+\mathrm{H}_{2}, \\
& \mathrm{CH}_{4}, \text { benzenes } \\
\rightarrow & \mathrm{C}_{6} \mathrm{H}_{5} \mathrm{CH}_{2} \mathrm{C}=\mathrm{CHCH}_{3}+\mathrm{H}_{2}, \\
& \mathrm{CH}_{4} \text {, benzenes } \\
\rightarrow & \mathrm{C}_{6} \mathrm{H}_{5} \mathrm{CH}_{2} \mathrm{CH}=\mathrm{CCH}_{3}+\mathrm{H}_{2}, \\
& \mathrm{CH}_{4}, \text { benzenes } \\
\rightarrow & \mathrm{C}_{6} \mathrm{H}_{5} \mathrm{CH}_{2} \mathrm{CH}=\mathrm{CHCH}_{2}+ \\
& \mathrm{H}_{2}, \mathrm{CH}_{4} \text {, benzenes }
\end{aligned}
$$

range. Radicals are formed as a result of these bond cleavages. The decomposition of these radicals lead to the stable products that we can detect in our final product analysis.

Cursory inspection of Scheme I indicates that cleavage of the vinylic $\mathrm{C}-\mathrm{H}$ bonds cannot posibly be a factor in these studies. On the other hand the $\mathrm{C}-\mathrm{H}$ bonds that are weakened by resonance stabilization can be important if the values of the vinylic carbon bond strengths are large. It should be noted that except for radicals that are resonance stabilized such as benzyl or radicals that have no low-lying decomposition channel such as methyl or phenyl large organic radicals decompose rapidly through $\beta$-bond fission under our experimental conditions and cannot attack the substrates.

The stability of 1-PHB-2 makes it impossible to work under overwhelmingly inhibited conditions, that is, with a sufficient concentration of another species (such as a methylated benzene) that captures all of the reactive radicals and leads to the formation of less reactive species such as benzyl. Benzyl type radicals under our reactive conditions cannot add or abstract and ultimately disappear by combination with themselves or other reactive radicals. In our usual experiments the ratio of inhibitor to target molecule is of the order of 50-1000 to 1 . However it appears that the rates of unimolecular decomposition of 1-PHB-2 are less than 2 orders of magnitude larger than for benzyl-hydrogen bond splits in methylated benzenes. In the present case we used inhibitor to target molecule ratios of 0,2 , and 8 to 1 . Thus it is necessary to consider the consequences of reactive radical attack on 1-PHB-2. The important reactions are hydrogen atom and methyl radical attack. The reactions and radicals that are formed are given in Scheme II.

Scheme III contains a listing of the radicals that are formed from the reactions in Schemes I and II and their pathways for decomposition. The important reactions are the two processes that can lead to acetylene formation. They are in both bases the results of the breaking of the vinylic C-C bonds from 1-PHB-2. However, from Scheme I we note the effect of benzyl resonance in lowering the bond energy for the benzyl-vinyl bond by $54 \mathrm{~kJ} / \mathrm{mol}$ in comparison to the bond energy for the vinyl-methyl bond. Thus even if there is a difference of a factor of 10 in the $A$ factor in favor of the latter, the rate constants will still

(8) Tsang, W. J. Am. Chem. Soc. 1985, 107, 2872

(9) Tsang, W.; Hampson, R. F. J. Phys. Chem. Ref. Data 1986, 15, 1087 .
Scheme III. Decomposition Pathways for Radicals Formed during 1-Phenyl-2-butene Decomposition

$\mathrm{C}_{6} \mathrm{H}_{5} \mathrm{CHCH}=\mathrm{CHCH}_{3} \rightarrow \mathrm{C}_{6} \mathrm{H}_{5} \mathrm{CH}=\mathrm{CHCH}=\mathrm{CH}_{2}+\mathrm{H}$

$\mathrm{C}_{6} \mathrm{H}_{5} \mathrm{CH}_{2} \mathrm{CH}=\mathrm{CHCH}_{2} \rightarrow \mathrm{C}_{6} \mathrm{H}_{5} \mathrm{CH}=\mathrm{CHCH}=\mathrm{CH}_{2}+\mathrm{H}$

$\mathrm{C}_{6} \mathrm{H}_{5} \mathrm{CH}_{2} \mathrm{C}=\mathrm{CHCH}_{3} \rightarrow \mathrm{C}_{6} \mathrm{H}_{5} \mathrm{CH}=\mathrm{C}=\mathrm{CHCH}_{3}+\mathrm{H}$

$\mathrm{C}_{6} \mathrm{H}_{5} \mathrm{CH}_{2} \mathrm{CH}=\mathrm{CCH}_{3} \rightarrow \mathrm{C}_{6} \mathrm{H}_{5} \mathrm{CH}_{2}+\mathrm{CHCCH}_{3}$ (propyne)

$\mathrm{C}_{6} \mathrm{H}_{4} \mathrm{CH}_{2} \mathrm{CH}=\mathrm{CHCH}_{3} \rightarrow$ thermally stable, will abstract

$\mathrm{C}_{6} \mathrm{H}_{5} \rightarrow$ thermally stable, will abstract

$\mathrm{CH}_{2} \mathrm{CH}=\mathrm{CHCH}_{3} \rightarrow \mathrm{CH}_{2}=\mathrm{CHCH}=\mathrm{CH}_{2}+\mathrm{H}$

$\mathrm{C}_{6} \mathrm{H}_{5} \mathrm{CH}_{2} \rightarrow$ thermally stable, will recombine with other radicals

$\mathrm{CH}=\mathrm{CHCH}_{3} \rightarrow$ acetylene $+\mathrm{CH}_{3}$

$\mathrm{C}_{6} \mathrm{H}_{5} \mathrm{CH}_{2} \mathrm{CH}=\mathrm{CH} \rightarrow \mathrm{C}_{6} \mathrm{H}_{5} \mathrm{CH}_{2}+$ acetylene

$\mathrm{CH}_{3} \rightarrow$ thermally stable, will abstract

be a factor of 20 slower. This illustrates the effect of the benzyl substitution. Note especially that there are no other processes that produce acetylene. Thus the yields of acetylene are directly traceable to the fundamental benzyl-vinyl bond-breaking processes regardless of the presence of any inhibitor. As will be seen below, the actual role of the inhibitor is to protect the integrity of our measurements on the internal standard that we use to calibrate our system. The inhibitor does not completely prevent a number of possible radical-induced decompositions of 1-PHB-2. Products from these processes do not play a role in our quantitative determinations.

The key factors in obtaining high-accuracy results from single-pulse shock tube work are the great simplifications in the reaction mechanism and the use of an internal standard reaction to calibrate for the conditions, especially the temperature, in the experiments. The consequence is that the uncertainties in the experimental measurements are reduced to that of the gas chromatographic analysis. These are of the order of a few percent in the concentration. This is equivalent to an uncertainty of about $1 \mathrm{deg}$ in temperature. This leads to very accurate determinations of rate expressions. The general methodology has been successfully used to give a complete picture of the decomposition of many organic compounds, and the accuracy of the rate expressions so obtained have been tested for many cases. ${ }^{5}$ Detailed discussion of uncertainties and error limits can be found in an earlier publication. ${ }^{5}$ Note that the new values for the heats of formation on the simple alkyl radicals which we recently proposed and which rationalized scores of investigations bearing on radical decomposition, hydrocarbon decomposition, and radical combination were all based originally on this type of shock tube work. ${ }^{8}$

\section{Experimental Section}

The experiments are carried out in a heated single-pulse shock tube maintained at $383 \mathrm{~K}$. All of the gas sampling system is maintained at temperatures close to or above this value. It is thus possible to work with very low volatility substances. Analysis of the products was by gas chromatography using a $30-\mathrm{m}$ poly (dimethylsiloxane) capillary column for all substances with carbon numbers 5 or higher. For the light hydrocarbons we use a dinonyl phthalate-coated silica column. This column eluted acetylene between propylene and isobutene. Allene eluted at the same time. From separate experiments, yields of allene did not exceed $4 \%$ of the acetylene concentration.

The 1-PHB-2 is from K \& $\mathrm{K}$ Chemicals. ${ }^{10}$ Gas chromatographic analysis indicated that it is mostly the trans compound with about $3 \%$ cis. There are also a number of other impurities including $n$-butylbenzene and sec-butylbenzene. In these molecules, benzyl resonance lowers the bond energy of one of the C-C bonds. Since these are much more labile than vinyl-benzyl bonds,

(10) Certain commercial materials and equipment are identified in this paper in order to specify adequately the experimental procedure. In no case does such identification imply recommendation or endorsement by the National Bureau of Standards nor does it imply that the material or equipment is necessarily the best available for the purpose. 
Table I. Composition of Reaction Mixtures

1. $1 \% 1$-phenyl-2-butene in argon

2. $1 \% 1$-phenyl-2-butene and $200 \mathrm{ppm} 1$-methylcyclohexene in argon

3. $1 \%$ 1,2,4-trimethylbenzene, $0.5 \%$ 1-phenyl-2-butene, and 100 ppm 1-methylcyclohexene in argon

4. $2 \%$ 1,2,4-trimethylbenzene, $0.25 \%$ 1-phenyl-2-butene, and 50 ppm 1-methylcyclohexene in argon

we observe under all conditions large quantities of their dissociation products. However, it is not possible to form acetylene from these starting materials. Here we use the same type of reasoning as given in Schemes I-III. Indeed the only way to form acetylene is by reactions of the ethylene and propylene products. These are thermally stable under our conditions, and their concentration levels (in comparison to the other molecules that are present) are so low so that they are protected from radical attack by the other compounds present in much larger quantities.

The internal standard used in these studies is the reverse Diels-Alder decomposition of 1-methylcyclohexene (1-MCH). We have previously established ${ }^{11}$ its rate expression for decomposition into 2-methyl-1,3-butadiene (isoprene) and ethylene as

$k\left(1-\mathrm{MCH} \rightarrow\right.$ isoprene $\left.+\mathrm{C}_{2} \mathrm{H}_{4}\right)=1 \times 10^{15}[\exp (-33500 / T)] / \mathrm{s}$

This standard is used because isoprene is not a reaction product in 1-PHB-2 decomposition and it elutes from our capillary column in a region where there are no interfering peaks. We estimate on the basis of similar studies and through intercomparisons with other reactions ${ }^{5}$ the uncertainties in the activation energy at 2.5 $\mathrm{kJ} / \mathrm{mol}$ and the rate constant at $20 \%$.

The scavenger used in these studies is 1,2,4-trimethylbenzene $(1,2,4-T M B)$. The sequence of the inhibitory reactions involving methyl and hydrogen atoms are

$$
\begin{aligned}
\mathrm{H}^{*}+1,2,4-\mathrm{TMB} & \rightarrow \text { dimethylbenzene }+\mathrm{CH}_{3}{ }^{*} \\
& \rightarrow \text { dimethylated benzyl* }+\mathrm{H}_{2} \\
\mathrm{CH}_{3}{ }^{*}+1,2,4-\mathrm{TMB} & \rightarrow \text { dimethylated benzyl }{ }^{*}+\mathrm{CH}_{4}
\end{aligned}
$$

Any other radicals can behave in the same manner. However, as noted earlier practically all the other organic radicals are either too unstable or insufficiently reactive under the conditions of our experiments.

Table I contains a listing of the mixtures that we have used. Only a few experiments were carried out with the $1 \% 1$-PHB-2 mixture in order to get some idea of the nature and distribution of the reaction products.

\section{Results}

The distribution of products from the shock-induced decomposition of 1-PHB-2 in the presence and absence of the scavenger 1,2,4-TMB can be found in Table II. For each of the mixtures with $1-\mathrm{MCH}$ we give the results of two runs at different temperatures. The important points to be noted are the changes in relative concentrations. We assume that acetylene is essentially a primary product and its concentration will not be affected by the absence or presence of the scavenger. Our results are in accord with the expectation that some of the reactive radicals will be removed by the 1,2,4-TMB. However, although there is a decrease in the yields of the lighter products (for example, propylene, butadiene) relative to that of acetylene as the amount of the inhibitor, 1,2,4-TMB, is increased, we cannot be certain that we have been able to stop completely the radical-induced decomposition. This is not unreasonable, since as noted earlier the thermal stability characteristics of 1-PHB-2 are not that much different from those of the inhibitor. Thus there approaches a point where our inhibitor will in fact be contributing to the pool of active radicals. It is interesting to note that the material balance with regard to $1-\mathrm{MCH}$ decomposition improves

(11) Tsang, W. Int. J. Chem. Kinet. 1978, 10, 599. with scavenger addition. Clearly in the absence of the scavenger, there are radical-catalyzed decomposition channels. However, as noted earlier, acetylene is not formed from any of these reactions.

For our purposes we concentrate on the acetylene from 1-PHB-2 decomposition and isoprene from 1-MCH decomposition. Figure 1 contains the comparative rate plots for the formation of acetylene from 1-PHB-2 decomposition and isoprene from 1-MCH decomposition. The rate constants are derived from the relations

$$
k(\text { acetylene })=\left([\text { acetylene }]_{\mathrm{f}} /[1-\mathrm{PHB}-2]_{\mathrm{i}}\right) / t
$$

$k($ isoprene $)=\left(\log \left(1-\left(X[\text { isoprene }]_{\mathrm{f}} /[1-\mathrm{MCH}]_{\mathrm{i}}\right)\right)\right) / X t$

where $X=1+\left(\left([\mathrm{MCH}]_{\mathrm{i}}-[\mathrm{MCH}]_{\mathrm{f}}-[\text { isoprene }]_{\mathrm{f}}\right) /[\right.$ isoprene $]_{f}$ ) and takes into account the possibility that some of the $1-\mathrm{MCH}\left([\mathrm{MCH}]_{\mathrm{i}}-[\mathrm{MCH}]_{\mathrm{f}}-[\text { isoprene }]_{\mathrm{f}}\right)$ will be decomposed through radical attack, $t$ is the total heating time, on the order of $500 \mathrm{~ms}$, and the subscripts $\mathrm{i}$ and $\mathrm{f}$ refer to initial and final concentrations. We have no means of determining how much isoprene is destroyed in this manner. Thus it is essential in the 1-MCH decomposition to obtain the best possible mass balance. This is attained when the scavenger is added. As will be seen below, in the absence of scavenger, comparative rate results are slightly different from those in its presence. The relation defining the rate constant for acetylene formation assumes negligible 1-PHB-2 disappearance. From the data in Table I it can be seen that this is attained in the studies with the scavenger. We assume that the conversion of the trans to the cis form will not affect out results. An interesting aspect of the data in Table $I$ is that we can extract rate constants for the trans $\rightarrow$ cis isomerization of 1-PHB-2 as well as the decomposition of $n$-butyl- and sec-butylbenzene. In all three cases they fall in the expected range.

The comparative rate expressions relating the rate constant for acetylene and isoprene formation in 1-PHB-2 and $1-\mathrm{MCH}$ decomposition are as follows:

$\log (k$ (acetylene $))=$

$$
(1.308 \pm 0.014)(\log (k \text { (isoprene })))-3.030 \pm 0.034
$$

$1 \%$ 1-PHB-2 and 200 ppm 1-MCH

$\log (k$ (acetylene $))=$

$$
(1.312 \pm 0.015)(\log (k(\text { isoprene })))-3.256 \pm 0.036
$$

$1 \%$ 1,2,4-TMB, $0.5 \%$ 1-PHB-2, and 100 ppm 1-MCH $\log (k$ (acetylene $))=$

$$
(1.304 \pm 0.034)(\log (k(\text { isoprene })))-3.198 \pm 0.087
$$

$2 \%$ 1,2,4-TMB, 0.25; 1-PHB-2, and 50 ppm 1-MCH

Substituting into these relations the rate expression for the reverse Diels-Alder decomposition of $1-\mathrm{MCH}$ given above, we obtain the following rate expressions for acetylene formation in 1-PHB-2 decomposition $k$ (acetylene) $=$ $3.8 \times 10^{16}(\exp (-43800 / T)) / \mathrm{s}, k($ acetylene $)=2.6 \times 10^{16}$. $(\exp (-43900 / T)) / \mathrm{s}$ and $k$ (acetylene $)=2.3 \times 10^{16}$ $(\exp (-43670 / T)) / \mathrm{s}$, respectively.

The last two expressions are virtually identical, while the first rate expression is about $30 \%$ larger. This is probably due to the contribution from the radical-induced decomposition of $1-\mathrm{MCH}$ and isoprene and is of the magnitude expected on the basis of our mass balance considerations. The agreement in the other two cases demonstrates that enough inhibitor has now been added so that the radical-induced decomposition no longer poses a serious problem. This is not surprising since the ratio of $1,2,4-\mathrm{TMB}$ to $1-\mathrm{MCH}$ are 100 and 400 to 1 , respectively. Clearly the 1-MCH will be "protected". If this is the case, 
Table II. Typical Gas Analysis Results from the Decomposition of 1-Phenyl-2-butene ${ }^{a}$

\begin{tabular}{|c|c|c|c|c|c|c|c|}
\hline \multirow[b]{2}{*}{ mixtures } & \multirow{2}{*}{$\begin{array}{l}1 \% 1-\mathrm{PHB}-2 \\
\text { in argon }\end{array}$} & \multicolumn{2}{|c|}{$\begin{array}{c}1 \% 1-\mathrm{PHB}-2,100 \mathrm{ppm} \\
1-\mathrm{MCH} \text { in argon }\end{array}$} & \multicolumn{2}{|c|}{$\begin{array}{l}1 \% 1,2,4-\mathrm{TMB}, 0.5 \% \\
1-\mathrm{PHB}-2,100 \mathrm{ppm} 1-\mathrm{MCH} \\
\text { in argon }\end{array}$} & \multicolumn{2}{|c|}{$\begin{array}{c}2 \% 1,2,4-\mathrm{TMB}, 0.25 \% \\
1-\mathrm{PHB}-2,50 \mathrm{ppm}(1-\mathrm{MCH}) \\
\text { in argon }\end{array}$} \\
\hline & & $T \simeq 1160 \mathrm{~K}$ & $T \simeq 1105 \mathrm{~K}$ & $T=1143 \mathrm{~K}$ & $T=1172 \mathrm{~K}$ & $T=1185 \mathrm{~K}$ & $T=1121 \mathrm{~K}$ \\
\hline \multicolumn{8}{|c|}{ (A) Normalized against Initial Mixture } \\
\hline methane & 8.3 & 6.6 & 2.0 & 5.8 & 11.4 & 17.6 & 4.5 \\
\hline ethane, ethene & 6.9 & & 2.2 & 4.2 & 8.2 & 8.8 & 1.9 \\
\hline propylene & 9.6 & 7.7 & 2.0 & 1.7 & 3.5 & 1.9 & 0.57 \\
\hline acetylene & 1.3 & 0.81 & 0.13 & 0.3 & 0.74 & 0.86 & 0.11 \\
\hline butenes & 1.5 & 1.3 & 0.5 & 0.45 & 0.8 & 0.75 & 0.39 \\
\hline 1,3-butadiene & 3.5 & 2.5 & 0.56 & 0.76 & 1.7 & 1.5 & 0.25 \\
\hline benzene & 2.5 & 1.7 & 0.4 & 0.57 & 1.2 & 1.2 & 0.23 \\
\hline toluene & 2.8 & 1.8 & 0.6 & 0.82 & 1.8 & 2.1 & 0.58 \\
\hline ethylbenzene & 3.4 & 2.5 & 0.4 & 0.5 & 1 & 0.56 & 0.12 \\
\hline$m, p$-xylene & $c$ & $\ldots$ & $\ldots$ & & $\ldots$ & $\ldots$ & \\
\hline styrene & 6.5 & 5.0 & 1.3 & 2.0 & 3.6 & 3.5 & 0.8 \\
\hline$o$-xylene & $\ldots$ & $\ldots$ & $\ldots$ & $\because$ & & & $\ldots$ \\
\hline allylbenzene & 5.8 & 4.6 & 1.4 & 1.1 & 2.1 & 1.2 & $\ldots$ \\
\hline sec-butylbenzene & 7.4 & 8.5 & 11.2 & 10.4 & 8 & $\ldots$ & $\ldots$ \\
\hline$n$-butylbenzene & 2.2 & 2.2 & 2.3 & 2.5 & 2.3 & 2.3 & 2.6 \\
\hline trans-1-PHB-2 & 860 & 860 & 916 & 945 & 895 & 890 & 961 \\
\hline cis-1-PHB-2 & 62 & 57 & 30 & 50 & 76 & 85 & 35 \\
\hline \multicolumn{8}{|c|}{ (B) Normalized against $1-\mathrm{MCH}$} \\
\hline isoprene & & 133 & 34 & 91 & 178 & 234 & 53 \\
\hline $1-\mathrm{MCH}$ & & 807 & 944 & 904 & 780 & 744 & 934 \\
\hline
\end{tabular}

${ }^{a}$ In units of $10^{3} \times$ mole fraction. Reaction time $\sim 500 \mathrm{~ms}$; pressure $\sim 3.2 \mathrm{~atm}$. $T$ based on isoprene yields. ${ }^{b}$ Composition: trans-1-PHB-2, 964; cis-1-PHB, 21; sec-butylbenzene, 12 ; $n$-butylbenzene, 2.6. ' No meaningful measurements. Xylenes are formed from the $\mathrm{H}$ atom induced decomposition of 1,2,4-TMB.

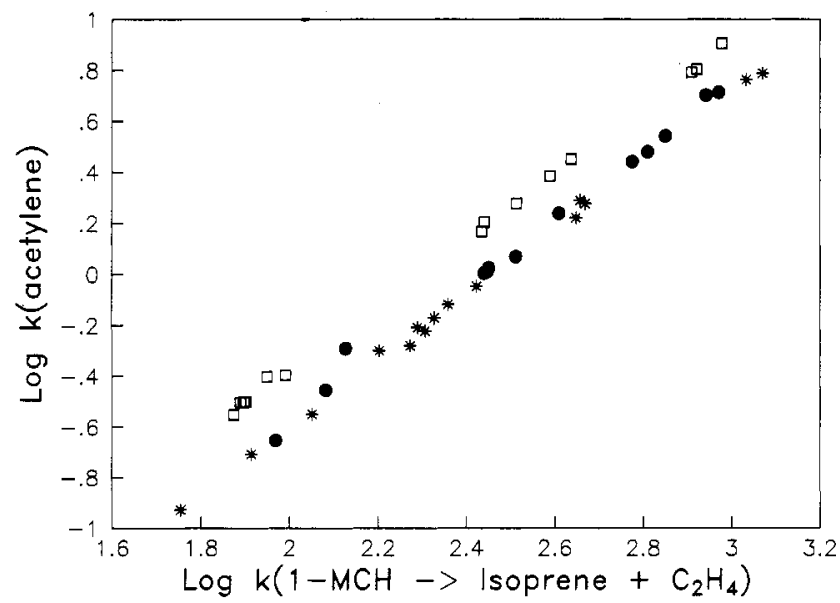

Figure 1. Comparative rate studies on the formation of benzyl and propenyl from 1-PHB-2 and 1-MCH decomposition: (ㅁ) $1 \%$ 1-PHB-2 and $200 \mathrm{ppm} 1-\mathrm{MCH}$ in argon; (*) $1 \%$ 1,2,4-TMB, $0.5 \%$ 1 -PHB-2, and 100ppm 1-MCH in argon; (๑) $2 \% 1,2,4-\mathrm{TMB}$, $0.25 \%$ 1-PHB-2, and $50 \mathrm{ppm} 1-\mathrm{MCH}$ in argon. Conditions: temperature, 1092-1221 K; residence time, $500 \mathrm{~ms}$; pressure, 2.5-3.5 atm.

then the similarity in results is fully consistent with our assumption that the acetylene is not formed by a radical-induced process. Our best rate expression for the breaking of the vinyl-benzyl bond is thus the average of our results in studies carried out in the presence of $1,2,4$ TMB or

$$
\begin{aligned}
& k(1-\text { PHB-2 } \rightarrow \text { benzyl }+ \text { propenyl })= \\
& 2.4 \times 10^{16}(\exp (-43780 / T))
\end{aligned}
$$

where the uncertainty in the activation energy is on the order of $5 \mathrm{~kJ} / \mathrm{mol}$ and that the absolute value of the rate constant is a factor of 1.4. The latter takes into account the uncertainty in our internal standard and is thus a realistic number. The former is merely a measure of the precision of the experiments. As will be seen below an analysis of systematic errors justifies the assignment of a larger uncertainty.

\section{Discussion}

We will now use our rate expression for the breaking of the benzyl-vinyl bond to derive the bond energy of the primary $\mathrm{C}-\mathrm{H}$ bond in propylene. From the usual assumption regarding the absence of temperature dependence for the reverse combination reaction, the relations are

$$
\Delta H(\text { reaction })=\Delta E(\text { activation energy })+R T
$$

or $\Delta H=373.4 \mathrm{~kJ} / \mathrm{mol}$ at $1150 \mathrm{~K}$. Since $\Delta H($ reaction $)=$ $H_{\mathrm{f}}$ (benzyl) $+H_{\mathrm{f}}$ (propenyl) $-H_{\mathrm{f}}(1$-PHB-2) at $1150 \mathrm{~K}$, substituting the heat of formation of benzyl and 1-PHB-2 leads to $H_{\mathrm{f}}$ (propenyl) $=252.7 \mathrm{~kJ} / \mathrm{mol}$ at $1150 \mathrm{~K}$. We have calculated the thermodynamic quantities of benzyl using the prescription of Benson and O'Neal ${ }^{12}$ and a value of 205 $\mathrm{kJ} / \mathrm{mol}$ for the heat of formation at $300 \mathrm{~K}$. This is 6 $\mathrm{kJ} / \mathrm{mol}$ higher than the number recommended by McMillen and Golden ${ }^{7}$ but is a value that we obtained some years ago on the basis of isobutylbenzene decomposition. ${ }^{5,13}$ This leads to a heat of formation of 186.2 $\mathrm{kJ} / \mathrm{mol}$ at $1150 \mathrm{~K}$. The heat of formation of 1 -PHB-2 at $1150 \mathrm{~K}$ is taken to be $66.5 \mathrm{~kJ} / \mathrm{mol}$ and is based on the heat of formation of butylbenzene and an average value of 120.1 $\mathrm{kJ} / \mathrm{mol}$ for the heat of dehydrogenation. ${ }^{14}$ Assuming that the heat capacity of propenyl is an average of that of propene and propyne leads to

$$
\mathrm{BDE}(\text { propene } \rightarrow \text { propenyl }+\mathrm{H})=465.3 \mathrm{~kJ} / \mathrm{mol}
$$

There have been no previous measurements of this bond dissociation energy. However, it should not be too far off from the value for ethylene.

McMillen and Golden ${ }^{7}$ have outlined an alternative procedure for determining heats of formation of radicals

(12) O'Neal, H. E.; Benson, S. W. Free Radicals; Kochi, J., Ed.; Wiley: New York, 1973; Vol. II, p 275.

(13) Tsang, W. Int. J. Chem. Kinet. 1969, 1, 245

(14) Stull, D. R.; Westrum, E. F.; Sinke, G. C. The Chemical Thermodynamics of Organic Compounds; Wiley: New York, 1968; p65.

(15) Robaugh, D.; Tsang, W. J. Phys. Chem. 1986, 90, 5363.

(16) Robaugh, D.; Stein, S. E. Int. J. Chem. Kinet. 1981, 13, 445. 
from this type of experiment. It involves the assumptions that the reverse reaction has no barrier at $0 \mathrm{~K}$ and the heat capacity of the transition state is that derived from the Gorin model. Golden ${ }^{17}$ has used our data and calculated results that are virtually identical with that presented here.

The $A$ factor for acetylene formation, $2.4 \times 10^{16} / \mathrm{s}^{-1}$, is large in comparison to that for processes that involve the breaking of a benzyl-alkyl bond. ${ }^{16}$ In these cases, $A$ factors are about 1 order of magnitude smaller. Our high number is reflected in the rate constant of the reverse recombination reaction. It is of interest to calculate the combination rate constant for benzyl and propenyl with our $A$ factor. From the estimated entropies we find that $\Delta S=$ $162.2 \mathrm{~J} /(\mathrm{mol} \mathrm{K})$. Substitution into the relation

$$
A_{\mathrm{f}} / A_{\mathrm{b}}=[\exp (\Delta S / R)] / e R T
$$

where the term $e R T(=0.224 T$, in atm, liter units) arises from the fact that we are considering a dissociation reaction where two compounds are being formed from one starting species, leads to $A_{\mathrm{b}}=k_{\mathrm{b}}=2 \times 10^{10} \mathrm{~L} /(\mathrm{mol} \mathrm{s})$, with an uncertainty of a factor of 3 . It is much larger than the values for comparable processes involving alkyl radicals. Thus a comparable calculation for ethylbenzene decomposition using the data of Robaugh and Stein ${ }^{16}$ leads to a combination rate constant for methyl and benzyl of $5 \times$ $10^{9} \mathrm{~L} /(\mathrm{mol} \mathrm{s})$. However, we note that if the geometric mean rule holds for these two radicals, this implies that the combination rate constant for two benzyl radicals at $1150 \mathrm{~K}$ is $3.2 \times 10^{8} \mathrm{~L} /(\mathrm{mol} \mathrm{s})$. This is an extremely small value.

The present results are crucially dependent on the postulated mechanism. We now consider possible sources of uncertainties in our measurements. We have assumed that all the acetylene must be formed from the cleavage of the benzyl-vinyl $\mathrm{C}-\mathrm{C}$ bond and that this will be followed by $\beta-C-C$ bond cleavage. While we believe that these embody the main reactions, the fact that we are making a slope measurement means that small contributions from minor reaction channels may lead to substantial errors. We have previously considered effects arising from vinylmethyl bond cleavage and the lifetime of the propenyl radical. Another possible source of uncertainty is the assumption of $\beta-C-C$ bond cleavage in propenyl decomposition and ignoring the possibility of a 1-3 bond shift leading to an allyl radical, which will be fairly stable under our conditions. This assumption is based on the behavior of alkyl radicals. In the present case there may be some enhancement due to the much larger reaction exothermicity for the 1-3 shift (in excess of $60 \mathrm{~kJ} / \mathrm{mol}$ ). However, since we are dealing with a doubly bonded structure there will be an extra degree of strain in the transition state. Furthermore, in the decomposition of 0 -iodotoluene where we make the o-methylphenyl radical, which is structurally very similar to propenyl, there does not appear to be any evidence for such a shift. ${ }^{15}$ It should be noted that if such an effect is to make a contribution, it will bias the results toward higher activation energies. The $A$ factor for 1-3 $\mathrm{H}$-shift must be smaller than the "normal", $10^{13} / \mathrm{s}^{-1}$ value for $\beta-\mathrm{C}-\mathrm{C}$ bond fission and this must be compensated for by a lower activation energy if this process is to make any contribution. Thus all of the possible errors appear to be toward higher activation energies. On this basis, we believe that to some extent our activation energy is an upper limit. A lower limit is set by the combination rate constant for benzyl and methyl radicals of $5 \times 10^{9} \mathrm{~L} /(\mathrm{mol} \mathrm{s})$. Scaling our activation energy to obtain the same rate constant will lead to a value of $351.2 \mathrm{~kJ} / \mathrm{mol}$ or a bond dissociation energy of $452.7 \mathrm{~kJ} / \mathrm{mol}$. Taking the average of the two values for the bond dissociation energy, we arrive at 459 $\pm 10 \mathrm{~kJ} / \mathrm{mol}$ as the most likely value.

It is interesting to consider the consequences of a bond dissociation energy in the $435 \mathrm{~kJ} / \mathrm{mol}$ range. Assuming our rate constant to be correct, this will imply an $A$ factor of $8 \times 10^{14} \mathrm{~s}^{-1}$ and a rate constant for combination of close to $6.6 \times 10^{8} \mathrm{~L} /(\mathrm{mol} \mathrm{s})$. This strikes us as an extremely low and unlikely value. Even more unlikely is the highest reported value for the $\mathrm{C}-\mathrm{H}$ bond energy in ethylene since this will lead to an $A$ factor of $7 \times 10^{16} \mathrm{~s}^{-1}$ and a recombination rate of $6.3 \times 10^{10} \mathrm{~L} /(\mathrm{mol} \mathrm{s})$. On the other hand, a somewhat higher rate constant for vinyl radical combination is in line with increasing evidence for a very small disproportionation to combination rate constant ratio for vinyl radicals reacting with itself. ${ }^{18}$

Acknowledgment. We are grateful to Dr. David Golden for his careful review and for helping us detect several errors in the original manuscript.

Registry No. 1-PHB-2, 1560-06-1; $\mathrm{CH}=\mathrm{CHCH}_{3}, 115-07-1$. 